\title{
A First Look: Disparities in COVID-19 Mortality Among US-Born and Foreign-Born Minnesota Residents
}

\section{Kimberly M. Horner ${ }^{1}$ (D) . Elizabeth Wrigley-Field ${ }^{2}$ D . Jonathon P. Leider ${ }^{3}$}

Received: 16 May 2021 / Accepted: 16 July 2021 / Published online: 2 August 2021

(C) The Author(s), under exclusive licence to Springer Nature B.V. 2021

\begin{abstract}
This research brief provides one of the first examinations of the impact of COVID19 mortality on immigrant communities in the United States. In the absence of national data, we examine COVID-19 deaths in Minnesota, historically one of the major U.S. refugee destinations, using individual-level death certificates obtained from the Minnesota Department of Health Office of Vital Records. Minnesota's foreign-born crude COVID-19 death rates were similar to rates for the US-born, but COVID-19 death rates adjusted for age and gender were twice as high among the foreign-born. Among foreign-born Latinos, in particular, COVID-19 mortality was concentrated in relatively younger, prime working age men. Moreover, the placebased and temporal patterns of COVID-19 mortality were quite distinct, with the majority of US-born mortality concentrated in long-term care facilities and late in 2020, and foreign-born mortality occurring outside of residential institutions and earlier in the pandemic. The disparate impacts of COVID-19 for foreign-born Minnesotans demonstrate the need for targeted public health planning and intervention in immigrant communities.
\end{abstract}

Keywords Health disparities · Immigration · COVID-19

Kimberly M. Horner

horne184@umn.edu

1 Humphrey School of Public Affairs, University of Minnesota, 301 19th Ave S, Minneapolis, MN 55455, USA

2 Department of Sociology, University of Minnesota, 267 19th Ave S, Minneapolis, MN 55455, USA

3 School of Public Health, University of Minnesota, 420 Delaware St SE, Minneapolis, MN 55455, USA 


\section{Introduction}

In 2020, the US reported over 20 million cases of COVID-19 and over 350,000 deaths. Rising concerns surrounded effects on marginalized communities, as COVID-19 disproportionately impacted communities of color (Abedi et al., 2021; Millett et al., 2020; Pan et al., 2020). Less is known about the impacts of COVID19 on other sub-populations, such as immigrants. Understanding these impacts could allow for the development of more targeted interventions in the case of future public health crises.

This study focuses on COVID-19 mortality disparities present in Minnesota, a mid-sized US state with a population of 5.6 million people, including an immigrant population of nearly 500,000 (see Online Resource Table 1). A significant number of refugees, primarily Hmong and Somali, are a part of this population, and the state is the principal destination for secondary refugee movement in the US (Mossaad et al., 2020). It is also a state with stark disparities between nonHispanic whites and communities of color with respect to COVID-19 cases, hospitalizations, and deaths (MN.gov, 2021; Wrigley-Field et al., 2020). Focusing on Minnesota, this study adds to the growing literature examining state-level impacts of COVID-19 (see for example Chen et al., 2021; Cordes \& Castro, 2020; Tatar et al., 2021).

Theoretically, there may be expectation of lower COVID-19 mortality among immigrants than US-born residents. Literature documents a healthy immigrant effect-where immigrants tend to be healthier than US-born residents (Kennedy et al., 2015). However, research also finds that immigrant health tends to converge with US-born health over time (Antecol \& Bedard, 2006). This is significant, as the majority of immigrants to the US have been in the country for 10 years or more. In addition, in pre-pandemic times, better health outcomes among immigrants were consistent across all ICD-10 disease categories except infectious diseases and external causes (Aldridge et al., 2018).

Social, medical, economic and legal considerations contribute to the risk of COVID-19 among immigrants (summarized by Clark et al., 2020). First, social factors correlated with the spread of COVID-19, such as living in multi-generational housing that may expose the elderly to working-age and school-aged individuals, are more common among immigrants (Glick \& Van Hook, 2002; Kocchar \& Cohen, 2011). In addition, limited English proficiency may cause challenges in navigating health services and understanding public health recommendations. Second, health care access is more limited among the foreignborn. Immigrants are less likely to have health insurance or access to routine care (Derose et al., 2009). Although COVID-19 testing is free for all, there is no guarantee that care will be covered without insurance (NILC, 2020). Third, economic necessities may prevent immigrants from social distancing; immigrants are more likely to work in frontline jobs and federal CARES funding excluded many immigrants, making continued work and exposure essential (Gelatt, 2020; Kerwin \& Warren, 2020; NILC, 2020). Finally, challenges are exacerbated for immigrants concerned about immigration status. While USCIS announced that COVID-19 
testing and treatment would not negatively impact immigrants, confusion and fear of repercussions nonetheless hinder access (Bernstein et al., 2020; USCIS, 2020). As Page et al. (2020) note, "Expecting [immigrants] to trust the government now, during the COVID-19 crisis, is naive at best." These factors that differentiate the immigrant community, along with research indicating the disparate impacts of COVID-19 by race and ethnicity (Andrasfay \& Goldman, 2021; Rodriquez-Diaz et al., 2020), mean it is likely that immigrant communities are disproportionately suffering the effects of COVID-19. In order to address potentially disparate impacts from COVID-19 and future public health crises, the US must consider these complex circumstances faced by immigrant communities (Whitehouse.gov, 2021).

Little research has characterized how immigrant populations are impacted by COVID-19. There exists a dearth of data to assess these impacts. Demographic characteristics collected by the CDC COVID-19 Case Report Form do not include nativity and immigration status (CDC, 2020). While some have called for the collection of these data, collecting immigration status raises serious challenges (Langellier, 2020). The solicitation of immigration status may produce a "chilling effect", as studies have found that immigrants may avoid services due to fear of legal restrictions or repercussions (Bernstein et al., 2020; Kim et al., 2019). While it may be potentially less harmful to collect nativity data, studies have shown that suspicions of "illegality" or criminal activity are associated with certain countries of origin, especially when combined with social markers such as education, language, and occupation-raising concern that collecting this data may also impede public health efforts (Flores \& Ariela, 2018).

One source of data that contains information about both COVID-19 and nativity status are death certificates. While national COVID-19 death certificate data released by the CDC does not yet include information on nativity status, statebased analyses can illuminate impacts of COVID-19 on immigrant communities, specifically how COVID-19 mortality trends differ between US-born and foreignborn residents.

Our analysis contributes three comparisons by nativity in order to characterize the pandemic's impacts. These include a comparison of (1) COVID-19 mortality rates (2) the temporal distribution of COVID-19 deaths and (3) the location of COVID-19 deaths.

\section{Methods}

This manuscript uses death certificate data from Minnesota, collected in real-time during 2020, and analyzed in 2021. We employ descriptive statistics on demographics of decedents, and construct crude and age- and gender-adjusted mortality rates, as well as a zero-inflated negative binomial regression model to understand correlates of COVID-19 mortality in Minnesota, with a particular focus on nativity. 


\section{Data}

\section{Death Count Data}

Analysis is based on information recorded on Minnesota death certificates obtained from the Minnesota Department of Health Office of Vital Records. These records represent the count of deaths among Minnesota residents (Minnesotans) in Minnesota from January 1, 2020 to December 31, 2020, captured in the state's mortality files as of June 23, 2021. ${ }^{1}$

COVID-19 deaths were identified by examining International Classification of Disease (ICD) codes recorded for both immediate and underlying causes of death. Deaths are attributed to COVID-19 when a cause of death is recorded as ICD-10 code "U07.1 COVID-19, virus identified." This code indicates that the decedent received a positive result on a COVID-19 test.

Decedents' nativity status is established based on an individual's place of birth recorded on the death certificate. Nativity and other demographic information is provided by an informant, such as a close family member. These data may be incomplete, especially in cases where an informant cannot be found. Descriptive statistics include all cases of COVID-19 mortality, regardless of missing demographic information, while adjusted rates and the statistical analysis include only death certificates with complete race, nativity, gender, and age data.

\section{Population Data}

To construct population denominators, we used American Community Survey (ACS) 2015-2019 five-year survey data. Five years of data provides more stable population estimates for the small cell sizes associated with populations disaggregated by race, age, and gender. Explorations of 2015-2019ACS data demonstrate that estimates of the foreign-born population have remained stable.

Multi-race individuals were assigned to a single category using the race-bridging algorithm developed by Liebler and Halpern-Manners (Liebler \& Halpern-Manners, 2008). Those who indicated Latino ethnicity were classified as Latino and all other racial categories are limited to non-Latino individuals.

\section{Age- and Gender-Standardized Analysis}

Direct age- and gender-standardization provides a more meaningful comparison of COVID-19 mortality due to the higher rates of COVID-19 mortality at older ages and among men (Bischof et al., 2020; Famularo, 2020). Differences in population composition, such as divergent age distributions, can substantially influence crude COVID-19 mortality rates and distort comparisons between populations (Dowd et al., 2020). Analysis re-weights each age- and gender-specific death rate using a

\footnotetext{
1 We excluded deaths that occurred in Minnesota to people who were not listed as residents of Minnesota (approximately 3\% of COVID-19 deaths). This exclusion does not meaningfully change our results.
} 
standard population. We construct 15 -year age intervals, beginning at age 20 and top coded at age 65 . Standard population weights used are those of the entire population of Minnesota as recorded in the 2015-2019 5-year ACS estimates.

\section{Statistical Analysis}

While our death data represent a census of the population deaths and hence do not have sampling error, we use a zero-inflated negative binominal regression to confirm that the association of nativity with mortality, net of other variables, is statistically significant and thus unlikely to represent noise (Online Resource Table 2) (Alexander, 2015). We controlled for race, age, age-squared, and gender and include an interaction term for race and nativity status. Logged gender and age subpopulation data from the 2015 to 2019 Minnesota 5-year ACS were used as an offset term, and Asian deaths were dropped due to small population sizes for US-born Asians at older ages.

\section{Results}

Crude counts of COVID-19 mortality largely reflect demographic realities of the state- $89.5 \%$ of COVID-19 deaths in 2020 were among US-born Minnesotans who comprise $91.6 \%$ of Minnesota's population (see Online Resource Table 1). Table 1 characterizes Minnesota's COVID-19 deaths, disaggregated by nativity status and race/ethnicity. The foreign-born have a younger mean age of COVID-19 associated mortality compared to the US-born $(72.5$ vs. $82.0, p<0.001)$. There are also differences in demographic characteristics across different racial/ethnic categories within foreign-born deaths. Foreign-born Latino COVID-19 deaths, for example, have a mean age in the low 60s, approximately 70 percent of these deaths occurred among males, and over 60 percent of these decedents did not have a high school diploma (Table 1). This is a lower mean age, larger proportion of male, and lower educational attainment than COVID-19 deaths among other foreign-born or US-born populations.

\section{Characterizing COVID-19 Mortality Among Minnesota's US- and Foreign-Born}

Crude COVID-19 mortality is used to understand the overall relationship between COVID-19 mortality among US- and foreign-born Minnesotans. Minnesota's foreign-born crude COVID-19 mortality in 2020 was 143.0 deaths per 100,000 people, while Minnesota's US-born crude COVID-19 mortality was 138.4 per 100,000. However, when crude COVID-19 mortality is broken down by age, race, and nativity, crude rates appear higher among the foreign-born (Fig. 1).

Minnesota's foreign-born population is concentrated in working age adults compared to the US-born (Fig. 2). While white US-born and foreign-born COVID-19 deaths in Minnesotan have a similar age distribution, the Latino foreign-born display a COVID-19 mortality that is concentrated among the working-age (Fig. 2). The 







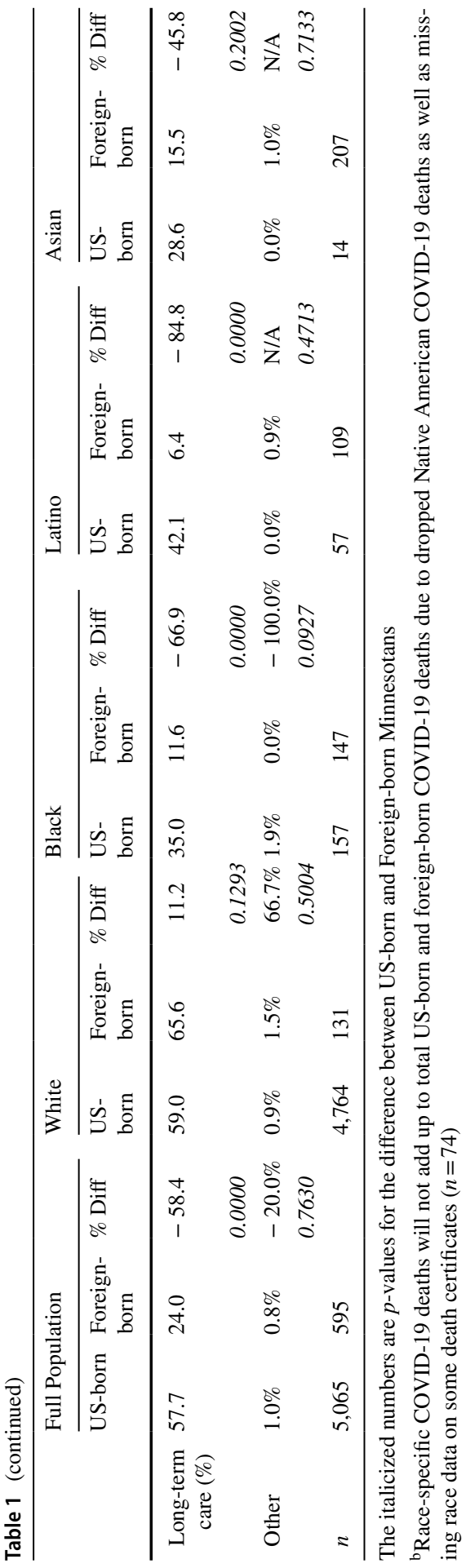




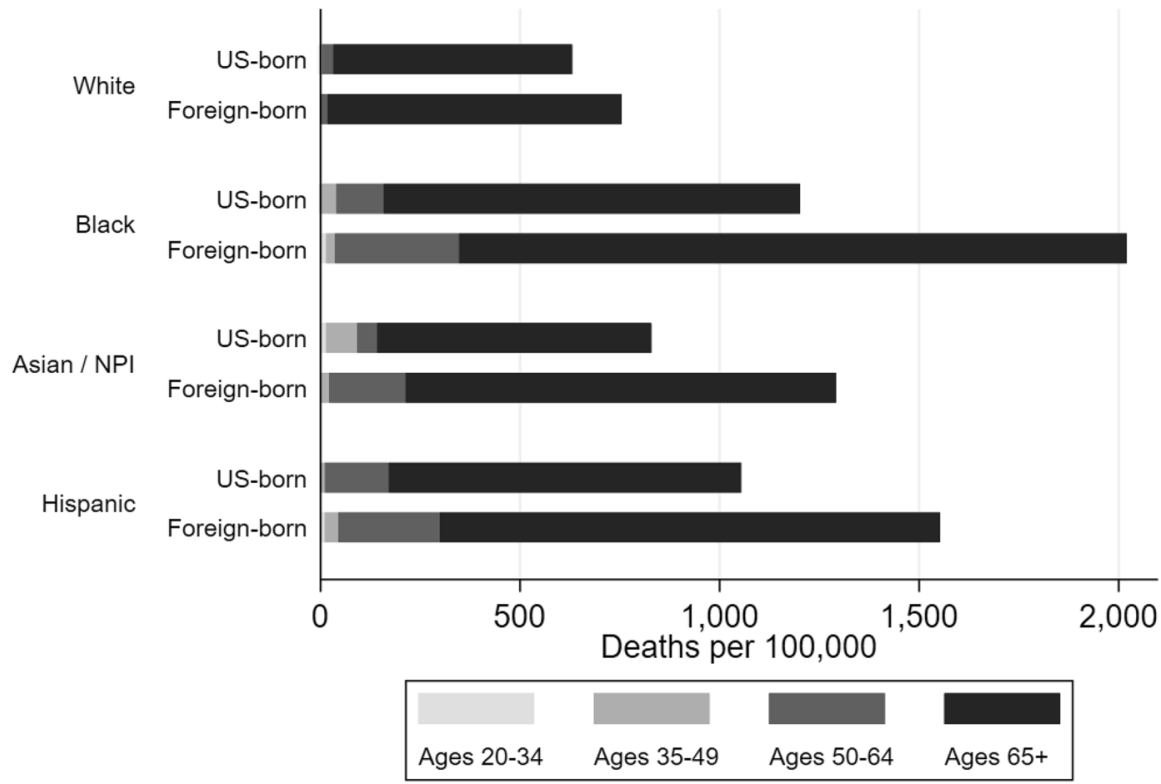

Fig. 1 Crude COVID-19 mortality by nativity and race/ethnicity
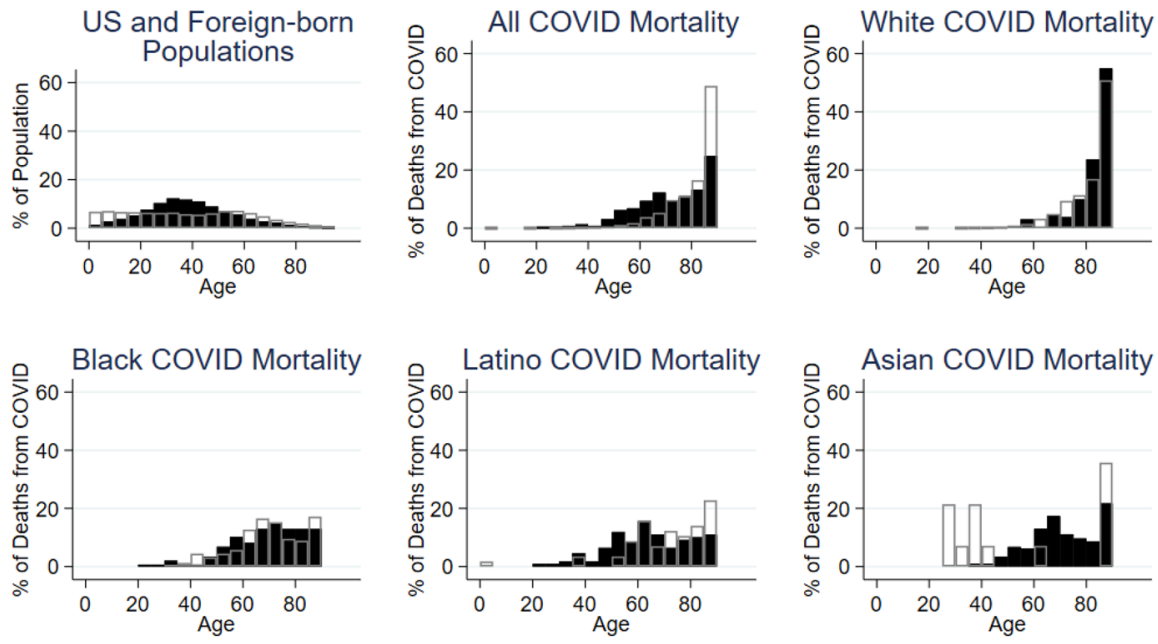

Foreign-born

\section{US-born}

Fig. 2 Age distribution of Minnesota population and COVID-19 mortality, by nativity and race/ethnicity. Age categories for population data and COVID-19 deaths are top-coded at age 90 
US-born Asian population is very small, with few COVID-19 deaths in this population $(n=14)$, however the foreign-born Asian population and COVID-19 deaths are substantial.

Age- and gender-specific COVID-19 mortality rates for US- and foreign-born Minnesotans capture disparities in COVID-19 mortality that may be masked by differences in age and gender distribution. The foreign-born age- and gender-adjusted COVID-19 mortality rate was 261.4 deaths per 100,000 compared to 129.7 per 100,000 among the US-born. A negative binomial regression model confirms that the association between nativity and COVID-19 mortality remains significant when controlling for age, age-squared, gender, and race (Online Resource Table 2). A term for interaction between race and nativity was significant for foreign-born Black and Latino, indicating that being foreign-born is associated with significantly increased risk for Blacks and Latinos compared to the risk associated with being foreign-born for Whites.

Similar to the rest of the US, Minnesota saw COVID-19 mortality concentrated in long-term care facilities and a large spike in COVID-19 mortality in November and December 2020. Death certificate data reveals that $54.1 \%$ of all 2020 Minnesotan COVID-19 deaths occurred in long-term care facilities, and $55.1 \%$ occurred in the months of November and December.

Temporal and place-specific distribution of COVID-19 mortality among foreignborn and US-born Minnesotans are displayed in Table 2. COVID-19 age- and gender-adjusted mortality rates are higher among foreign-born individuals than among the US-born throughout 2020. Rates are especially high among the foreign-born through the fall of 2020, with more comparable rates during the months of November and December. Disparities are highest when analysis is limited to deaths among the general population living outside of long-term care facilities, where age- and gender-adjusted COVID-19 is approximately 138 per 100,000 deaths (or approximately $250 \%$ ) higher among the foreign-born compared to the US-born.

\section{Discussion}

Foreign-born Minnesotans died of COVID-19 at twice the age- and gender-adjusted rate of the US-born. While racial disparities in COVID-19 mortality have been demonstrated, they do not account for all COVID-19 impacts on the immigrant population. Relative to the US-born, working-age immigrants are disproportionately impacted by COVID-19 in Minnesota. This may be related to the high proportion of foreign-born workers in front-line essential jobs with a higher risk of exposure (Gelatt, 2020; Kerwin \& Warren, 2020).

COVID-19 presents policy challenges for public health in Minnesota and across the US. While COVID-19 "does not discriminate on the basis of immigration status" the social and political systems in which immigrants work and live do discriminate (Cholera et al., 2020). The pandemic "has shed a harsh light on inequities within the US immigration system that have long denied immigrant, refugee, and asylum seeker populations of their rights to health and security" (Okonkwo et al., 2020). Given the profound issues faced by communities of color and immigrant 


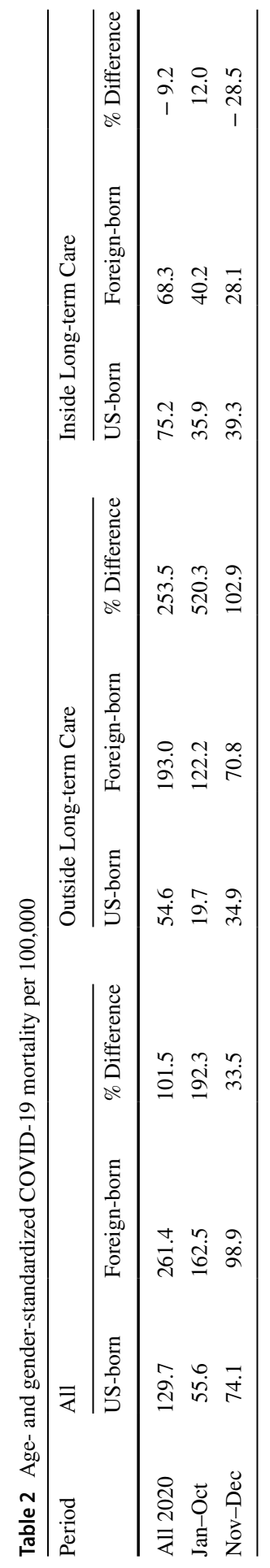


communities specifically, there are numerous, actionable research and policy opportunities to mitigate current and future public health crises.

Further research is needed across states and nationally to characterize the impact of COVID-19 on immigrant communities. Results of this analysis reflect the immigrant population in Minnesota, which includes larger Asian and Black immigrant shares than the US as a whole, resulting from Hmong and Somali refugee resettlement. However, nativity differences within and across racial groups highlight the importance of descriptive work to better understand the populations at risk and the sources of risk within immigrant communities. Public health interventions will be more effective when not only considering immigrants as a homogenous group, but also identifying differences in race/ethnicity, age, gender, education, and residence and their COVID-19 impacts.

To further protect immigrant communities, public health should collaborate with foreign-born communities to understand the lived reality of this analysis. Although the Trump administration has recently been replaced, his administration was not the beginning nor the end of xenophobic policy in the US (Lee, 2019). There remain well-founded fears that may negatively impact public health efforts to reach immigrant populations (Callaghan et al., 2019). By collaborating with immigrant-serving organizations and leaders, public health officials may more effectively reach communities with educational as well as medical interventions in the event of future crisis (Behbahani et al., 2020).

\section{Limitations}

Limitations of this study are primarily related to mis-reported data. First, nativity may be misreported due to informant error or fear of enforcement repercussions. Second, COVID-19 deaths may be underreported, especially among those who died at home or early in the pandemic without confirmed testing. These errors would likely cause an underestimate of foreign-born COVID-19 mortality. Third, mortality rates by nativity are dependent on knowing the true size of the immigrant population in Minnesota. Unauthorized immigration and misreporting make it difficult to identify immigrant populations, and estimates may be additionally compromised by changes in mobility patterns during the pandemic. Finally, the moderate size of Minnesota's immigrant population necessitates a somewhat coarse analysis (15-year age groups) in order to maintain cell sizes large enough to reasonably analyze.

\section{Conclusions}

Broad disparities in COVID-19 are reasonably well documented (Abedi et al. 2021; Millett et al., 2020). In this manuscript, we characterized nativity disparities among Minnesotans with respect to COVID-19 mortality in 2020. Disparities by race and ethnicity within US-born populations are profound, but so too are the disparities across US- and foreign-born groups. After accounting for age and gender differences across groups, foreign-born Minnesotans died at twice the rate of US-born 
Minnesotans due to COVID-19. In addition, the peaks in COVID-19 mortality at the end of 2020 and within long-term care facilities overshadow the experience of immigrant communities - which faced high early mortality rates and significant losses among those living outside long term care. More research and policy work alike can and must be done to ameliorate these inequities for the remainder of the COVID-19 pandemic and pandemics to come.

Supplementary Information The online version contains supplementary material available at https://doi. org/10.1007/s11113-021-09668-1.

Acknowledgements We thank Dr. Tom VanHeuvelen, Dr. Audrey Dorelien, and Dr. Jack DeWaard for their constructive conversation and comments in support of this project.

Author Contributions $\mathrm{KH}$ is the primary author, designed analysis, conducted analysis, and drafted text. EWF designed analysis, conducted analysis, and edited text. JPL designed analysis and edited text.

Funding This project was supported by the Eunice Kennedy Shriver National Institute of Child Health and Human Development via the Minnesota Population Center (P2CHD041023) and a Sustainable Development Goals Rapid Response Grant, a College of Liberal Arts Seed Grant, and during initial data processing stages the Fesler-Lampert Chair of Aging Studies, all at the University of Minnesota. None of the sponsors had any role in study design; collection, analysis, and interpretation of data; writing the report; and the decision to submit the report for publication.

Data Availability We cannot share disaggregated data due to our data use agreement with the Minnesota Department of Health. The original data can be obtained from the Minnesota Department of Health Office of Vital Records.

Code Availability Code can be made publicly available.

\section{Declarations}

Conflict of interest The authors declare no conflicts of interest.

Ethical Approval This study was deemed exempt from full review by the University of Minnesota institutional review board (STUDY00012527).

\section{References}

Abedi, V., Olulana, O., Avula, V., Chaudhary, D., Khan, A., Shahjouei, S., Li, J. \& Zand, R. (2021). Racial, economic, and health inequality and COVID-19 infection in the United States. Journal of racial and ethnic health disparities, 8(3), 732-742.

Aldridge, R. W., Nellums, L. B., Bartlett, S., Barr, A. L., Patel, P., Burns, R., Hargreaves, S., Miranda, J. J., Tollman, S., Friedland, J. S., \& Abubakar, I. (2018). Global patterns of mortality in international migrants: A systematic review and meta-analysis. The Lancet (British Edition), 392(10164), 2553-2566.

Alexander, N. (2015). What's more general than a whole population? Emerging Themes in Epidemiology, 12(1), 11-11.

Andrasfay, T., \& Goldman, N. (2021). Reductions in 2020 US life expectancy due to COVID-19 and dispropotionate impact on the Black and Latino populations. Proceedings of the National Academy of Sciences, 118(5), e2014746118. 
Antecol, H., \& Bedard, K. (2006). Unhealthy assimilation: why do immigrants converge to American health status levels? Demography, 43(2), 337-360.

Behbahani, S., Smith, C. A., Carvalho, M., Warren, C. J., Gregory, M., \& Silva, N. A. (2020). Vulnerable immigrant populations in the New York Metropolitan Area and COVID-19: Lessons Learned in the Epicenter of the Crisis. Academic Medicine, 95(12), 1827-1830.

Bernstein, H., Gonzalez, D., Karpman, M., \& Zuckerman, S. (2020). Amid confusion over the public charge rule immigrant families continued avoiding public benefits in 2019. Urban Institute.

Bischof, E., Wolfe, J., \& Klein, S. L. (2020). Clinical trials for COVID-19 should include sex as a variable. The Journal of Clinical Investigation, 130(7), 3350-3352.

Callaghan, T., Washburn, D. J., Nimmons, K., Duchicela, D., Gurram, A., \& Burdine, J. (2019). Immigrant health access in Texas: Policy, rhetoric, and fear in the Trump era. Bmchealth Services Research, 19(1), 342-348.

CDC. 2020. "How to Report COVID-19 Laboratory Data." edited by D.o.H.a.H. Services.Retrived March 1, 2021, from https://www.cdc.gov/coronavirus/2019-ncov/lab/reporting-lab-data.html.

Chen, Y., Glymour, M., Catalano, R., Fernandez, A., Nguyen, T., Kushel, M., \& Bibbins Domingo, K. (2021). Excess mortality in California during the coronavirus disease 2019 pandemic, March to August 2020. Jama Internal Medicine, 181(5), 705-707.

Cholera, R., Falusi, O. O., \& Linton, J. M. (2020). Sheltering in place in a xenophobic climate:COVID-19 and children in immigrant families. Pediatrics (Evanston), 146(1), e20201094.

Clark, E., Fredricks, K., Woc-Colburn, L., Bottazzi, M. E., \& Weatherhead, J. (2020). Disproportionate impact of the COVID-19 pandemic on immigrant communities in the United States. PLoS Neglected Tropical Diseases, 14(7), e0008484-e0008484.

Cordes, J., \& Castro, M. C. (2020). Spatial analylsis of COVID-19 clusters and contextual factors in New York City. Spatial and Spatio-Temporal Epidemiology, 34(1), 100355.

Derose, K. P., Bahney, B. W., Lurie, N., \& Escarce, J. J. (2009). Review: Immigrants and health care access, quality, and cost. Medical Care Research and Review, 66(4), 355-408.

Dowd, J. B., Andriano, L., Brazel, D. M., Rotondi, V., Block, P., Ding, X., Liu, Y., \& Mills, M. C. (2020). Demographic science aid in understanding the spread of fatality rates of COVID 19. Proceedings of the National Academy of Sciences, 117(18), 9696-9698.

Famularo, G. (2020). Comment on: COVID-19 and older adults: What we know. Journal of the American Geriatrics Society, 68(10), 2197.

Flores, R. D., \& Ariela, S. (2018). Who are the "illegals"? The social construction of illegality in the United States. American Sociological Review, 83(5), 839-868.

Gelatt, J. (2020). Immigrant workers: Vital to the US COVID-19 response, disproportionately vulnerable. Migration Policy Institute.

Glick, J. E., \& Van Hook, J. (2002). Parents' coresidence with adult children: Can immigration explain racial and ethnic variation? Journal of Marriage and Family, 64(1), 240-253.

Kennedy, S., Kidd, M. P., McDonald, J. T., \& Biddle, N. (2015). The healthy immigrant effect: Patterns and evidence from four countries. Journal of International Migration and Integration, 16(2), 317-332.

Kerwin, D., \& Warren, R. (2020). US foreign-born workers in the global pandemic: Essential and marginalized. Journal on Migration and Human Security, 8(3), 282-300.

Kim, G., Molina, U. S., \& Saadi, A. (2019). Should immigration status information be included in a patient's health record? AMA Journal of Ethics, 21(1), E8-16.

Kocchar, R., \& Cohn, D. (2011). Fighting poverty in a tough economy, Americans move in with their relatives. Pew Research Center.

Langellier, B. A. (2020). "Policy recommendations to address high risk of COVID-19 among immigrants." American Journal of Public Health, 110(8), 1137-1139. 1971.

Lee, E. (2019). America for Americans: A history of xenophobia in the United States. New York: Basic Books.

Liebler, C. A., \& Halpern-Manners, A. (2008). A practical approach to using multiple-raceresponse data: A bridging method for public-use microdata. Demography, 45(1), 143-155.

Millett, G. A., Jones, A. T., Benkeser, D., Baral, S., Mercer, L., Beyrer, C., Honermann, B., Lankiewicz, E., Mena, L., Crowley, J. S., Sherwood, J., \& Sullivan, P. S. (2020). Assessing differential impacts of COVID-19 on black communities. Annals of Epidemiology, 47, 37-44.

MN.gov. 2021. “COVID-19 Data by Race/Ethnicity.” Retrieved March 2, 2021, from https://mn.gov/ covid19/data/data-by-race-ethnicity/index.jsp. 
Mossaad, N., Ferwerda, J., Lawrence, D., Weinstein, J., \& Hainmueller, J. (2020). In search of opportunity and community: Internal migration of refugees in the United States. Science Advances, 6(32), eabb0295-eabb0295.

NILC. 2020. "Understanding the impact of key provisions of COVID-19 relief bills on immigrant communities." Retrieved March 1, 2021, from https://www.nilc.org/issues/economic-support/impact-ofcovid19-relief-bills-on-immigrant-communities/.

Okonkwo, N. E., Aguwa, U. T., Jang, M., Barre, I. A., Page, K. R., Sullivan, P. S., Chris, B., \& Stefan, B. (2020). COVID-19 and the US response: Accelerating health inequities. BMJ Evidence-Based Medicine. https://doi.org/10.1136/bmjebm-2020-111426

Page, K. R., Venkataramani, M., Beyrer, C., \& Polk, S. (2020). Undocumented U.S. immigrants and Covid-19. The New England Journal of Medicine, 382(21), e62-e62.

Pan, D., Sze, S., Minhas, J. S., Bangash, M. N., Pareek, N., Divall, P., Williams, C. M. L., Oggioni, M. R., Squire, I. B., Nellums, L. B., Hanif, W., Khunti, K., \& Pareek, M. (2020). The impact of ethnicity on clinical outcomes in COVID-19: A systematic review. EClinicalMedicine, 23, 100404-100404.

Rodriguez-Diaz, C. E., Guilamo-Ramos, V., Mena, L., Hall, E., Honermann, B., Crowley, J. S., Baral, S., Prado, G. J., Marzan-Rodriguez, M., Beyrer, C., \& Sullivan, P. S. (2020). "Risk for COVID-19 infection and death among Latinos in the United States: Examining heterogeneity in transmission dynamics." Annals of Epidemiology, 52, 46-53.

Tatar, M., Habibdoust, A., \& Wilson, F. A. (2021). Analysis of excess deaths during the COVID-19 pandemic in the state of Florida. American Journal of Public Health, 111(4), 704-707.

USCIS. (2020). "DHS Statement on Litigation Related to the Public Charge Ground of Inadmissibility." Department of Homeland Security. Retreived May 1, 2021, from https://www.dhs.gov/news/2021/ 03/09/dhs-statement-litigation-related-public-charge-ground-inadmissibility.

Whitehouse.gov. (2021). "National Strategy for the COVID-19 Response and Pandemic Preparedness." Retrieved March 1 2021, from https://www.nhpco.org/wp-content/uploads/White_House_National_ Strategy_for_the_COVID-19_Response.pdf.

Wrigley-Field, E., Garcia, S., Leider, J. P., Robertson, C., \& Wurtz, R. (2020). Racial disparities in COVID-19 and excess mortality in Minnesota. Socius: Sociological Research for a Dynamic World, 6, 237802312098091.

Publisher's Note Springer Nature remains neutral with regard to jurisdictional claims in published maps and institutional affiliations. 